\title{
Physiological characterization of SUB1 trait in rice under subsequent submergence and re-aeration with polyamine and salicylic acid interaction
}

\author{
Bipul Sarkar, Arnab Kumar De and M K Adak*
}

Plant Physiology, Biochemistry and Plant Molecular Biology Research Unit, Department of Botany, University of Kalyani, Kalyani 741235, West Bengal, India

Article history

Received: 14 September 2017

Accepted: 20 October 2017

Published: 27 November 2017

(c) Sarkar et al. (2017)

Editor

K K Sabu

Publisher

Horizon e-Publishing Group

Correspondence

M K Adak

凶mkadak09@gmail.com

\begin{abstract}
In the present study, the sensitivity of two chemical elicitors: polyamine (PA) and salicylic (SA) acid were exercised for submergence sensitivity in Swarna Sub1A rice variety. Under 5 days of submergence, the antioxidation responses were more distinguished in plants against control. Along with the anti-oxidation modules, significant changes in biomolecule loss were registered through lipid and protein oxidation by 1.91 and 1.46 -fold respectively. PA and SA treated plants were the reliever to recover the membrane potential. Total carbohydrate and reducing sugars were varied under submergence by down regulation of 36.66 and $44.44 \%$ as compared to control. This was also supported by regulation of a-amylase activity under submergence that also recovered significantly with PA and SA treatments against submergence. In association with carbohydrate metabolism, Under submergence Swarna Sub1A recorded to be prone with oxidative stress through $\mathrm{O}_{2}$. (1.55 fold) and peroxide (1.70-fold) over-accumulation but recovered as PA and SA applied. In both cases, sustenance of non-enzymatic anti-oxidant like total carotenoid and lycopene content were also contributory through down-regulation. The enzymatic anti-oxidation paths like SOD, GPX, CAT and GR were regulated by 11.11, 19.54, 13.65, 10.03\% declined respectively and thoroughly discussed with reference to PA and SA interactions.
\end{abstract}

Keywords: Rice; antioxidative enzymes; polyamine; salicylic acid, submergence, ROS
Abbreviations: CAT, Catalase; DNPH, 2,4-Dinitrophenylhydrazine; DNS, Dinitrosalicylic acid; EDTA, Ethylenediaminetetra acetic acid; GPX, Guaiacol peroxidase; GR, Glutathione reductase; $\mathbf{H}_{2} \mathbf{O}_{2}$, Hydrogen peroxide; MDA, Malondialdehyde; NBT, Nitroblue tetrazolium; $\mathbf{O}_{2 .}$; Superoxide; PA, Polyamine; PMSF, Phenyl methane sulphonyl fluoride; PVP, Polyvinyl pyrolidine; ROS, Reactive oxygen species; SA, Salicylic acid; SOD, Superoxide dismutase; TBA, Thiobarbituric acid; TCA, Trichloroacetic acid; $\boldsymbol{\beta}$-ME, $\beta$-Mercapto ethanol.

Citation: Sarkar B, De A K, Adak M K. Physiological characterization of SUB1 trait in rice under subsequent submergence and re-aeration with polyamine and salicylic acid interaction. Plant Science Today 2017;4(4):177-190. https://doi.org/10.14719/pst.2017.4.4.351

\section{Introduction}

Rice, the most staple crop in the world has been with the serious concern for its growth and sustainability from kinds of abiotic stresses. Excess of water in the form of submergence in rice fallows sets a bottleneck for both survival and productivity of indigenous land races. On an average $20 \%$ curtail of productivity is experienced globally in rice cultivation. In global rice cultivation, it covers $16 \%$ of total area under submergence stress with varying depth and durations. Submergence stress may be compounded with two major facets: induced water stress and anoxic/hypoxic stress. Due to abundance of water in soil, roots are suffered with 
poor hydraulic conductivity. Thus, osmotic potential of the tissues becomes depleted resulting water deficit stress (1). Alternatively, the dissolve oxygen in stagnant flood water for prolong days with turbidity and microbial invasion causes hypoxic/anoxic condition (2). This is more affected with an oxidative eruption of redox and causes accumulation of various Reactive Oxygen Intermediates/species (ROI/ROS). Typically rice plants with anoxic and hypoxic condition in submergence suddenly are exposed to high oxygen tension on recede of water level. The exposure of high intercellular oxygen concentration, particularly, with high irradiance creates an elevated redox with profuse ROS (3). Degeneration of cell membrane, loss of membrane permeability, disruption of energy yielding metabolism and finally oxidation of macromolecules are the outcome of such oxidative stress under submergence.

Plants are responsive to different chemical elicitors those influence the perception, transduction and cellular reactions to abiotic stress factors. In fact, the degrees of tissue sensitivity become a governing factor to the stress responses are variable to plant developmental stages as well as tissue types (4). Those chemical elicitors often modulate some cellular metabolic reactions and are reflected in changes of plant tolerance stresses. Out of few low molecular weight indigenous moieties, polyamines (PA) are the specific with features like aliphatic in nature, varied with unsaturation, soluble in cell sap, easily diffusible over the membrane (5). PA through its polycationic nature is mostly offered to bind cell and organelle membrane can influence the permeability, gene expression, modulation of different biochemical reactions. Metabolism of PA and with its expression profile is quite variable in sensitive and tolerant cultivars of crops subjected to different abiotic stressors. While osmotic, salinity, metal, temperature and oxidative stress are most discussed with PA interactions in cereal crops (mostly referred with rice), the submergence stress is less discussed. Submergence with its induced water deficit and accompanying oxidative exposure needs to be investigated with interfaces of PA interference. On the other hand, Salicylic acid (SA), a phenolic compound, is well justified with its efficiency mostly to biotic stress, in developing of ROS. In view of submergence related oxidative stress, the role of SA may also be important to the insights of cellular responses. In the present paper, the role of SA and PA in independent manner on influence of submergence stress reaction is highlighted. Swarna Sub1A, a recommended submergence tolerant line of rice is addressed with some contributing cellular responses under the influence of PA and SA in a precise concentration. The information may be useful for their selection rice varieties against submergence stress through some cellular reactions influenced by PA and SA activities.

\section{Materials and Methods \\ Experimental Plant Material:}

The experiment was performed in the laboratory of Plant Physiology and Plant Molecular Biology Unit, Department of Botany, University of Kalyani, W.B, India. Rice seeds of the variety Swarna Sub1A were collected from Rice Research Institute, Chinsurah R S, Hooghly, West Bengal 712103, India. Initially the seed's viability tests were done according to Hong and Ellis (2004) (6) under laboratory condition at temperature $26 \pm 2^{\circ} \mathrm{C}$ and RH $80 \%$ in a seed germinator. After sprouting, 7 days old seedlings were divided into 4 sets: Set 1 (control-without submergence and any treatments), Set 2 (submergence of seedlings without any treatment), Set 3 (submergence of seedlings pre-treated with $1 \mathrm{mM} \mathrm{SA}$ ) and Set 4 (submergence of seedlings pre-treated with $2 \mathrm{mM}$ Putrescine as PA). Set 3 and Set 4 were pre-treated with $1 \mathrm{mM}$ SA and $2 \mathrm{mM}$ PA for 24 hours before submergence $(7,8)$. On completion of treatments excluding control (not under submergence) seedlings were fully submerged under water in a cemented tank for 5 days. After 5 days of submergence Set 2, Set 3, Set 4 (without control) were kept in aeration for 1 day for recovery of seedling and stored at $-80^{\circ} \mathrm{C}$ for further use. This is to monitor the extent possible recovery of submergence (hypoxic/anoxic condition) to oxygenic condition of the seedlings.

\section{Biochemical Analysis:}

The biochemical analyses were done from shoot portions of the plant sample under various treatments according to standard methods.

\section{Total carbohydrate content:}

Determination of total carbohydrate was done by anthrone method according to Hedge and Hofreiter (1962) (9). 100mg of plant sample was taken in a test tube with $5 \mathrm{ml}$ of $2.5 \mathrm{~N} \mathrm{HCl}$ in a water bath for hydrolysis for $15 \mathrm{~min}$ and cool to room temperature. Then added some sodium carbonate for neutralize it until the effervescence disappear. Extraction makes up to $50 \mathrm{ml}$ by added distilled water and centrifuged $10000 \mathrm{x} g$ for 15 minutes. Then supernatant was collected and $1 \mathrm{ml}$ aliquots taken for reaction in test tubes. Thereafter, $4 \mathrm{ml}$ of anthrone reagent was added in every test tube and kept in a boiling water bath for 10 minutes. Tubes were cooled rapidly by tap water and read the absorbance of green to dark green color in a UVVIS spectrophotometer (Cecil) at 630nm. Then the amount of total carbohydrate was calculated from standard graph of glucose.

$\begin{aligned} & \text { Total carbohydrate present } \\ & \text { in 100mg of sample }\end{aligned}=\frac{\text { mg of glucose }}{\text { Volume of test sample }} \times 100$ 


\section{Reducing sugar content:}

Reducing sugars were determined by DNS method according to Miller (1972) (10) with slight modification. $100 \mathrm{mg}$ of sample was homogenized with $5 \mathrm{ml}$ of $80 \%$ of ethanol in a mortar pestle. The supernatant was collected and kept in a water bath for evaporation at $90^{\circ} \mathrm{C}$. When extract came to near $1 \mathrm{ml}$, samples were taken out and make up to $10 \mathrm{ml}$ solution to dissolve sugars with distilled water. $1 \mathrm{ml}$ of extract pipetted out in test tubes and added $2 \mathrm{ml}$ of DNS reagent. Then the samples were heated for 5 minutes in a boiling water bath and 1 ml of $40 \%$ Rochelle salt was added when the reaction mixtures were still warm. Thereafter, test tubes were cooled by tap water and absorbance of the dark red color of the reaction mixtures were read at 510nm in a UV-VIS spectrophotometer (Cecil). The amount of reducing sugars was calculated from the standard graph of glucose.

\section{a-Amylase activity:}

a-Amylase activity was determined according to Kruger (1972) (11) with slight modification. The $1 \mathrm{~g}$ of plant sample crushed with $10 \mathrm{mM}$ of ice-cold calcium chloride solution and kept for 3 hours at room temperature. The extract was centrifuged at $12000 \mathrm{x} \mathrm{g}$ at $4^{\circ} \mathrm{C}$ for 20 minutes and the supernatant was collected and used as enzyme extract. In test tubes, $1 \mathrm{ml}$ of enzyme extract and 1 $\mathrm{ml}$ of $1 \%$ starch solution were added and incubated at room temperature for 20 minutes. The reaction was stopped by addition of $2 \mathrm{ml}$ of dinitrosalicylic acid (DNS) reagent and heated for 5 minutes in a boiling water bath. While the tubes were still warm, $1 \mathrm{ml}$ of Rochelle salt (40\%) was added. Then solution was cooled by running tap water and volume make up to $10 \mathrm{ml}$ by addition of distilled water. The absorbance was read at $560 \mathrm{~nm}$ by a spectrophotometer using $1 \mathrm{ml}$ of water instead of enzyme extract in a test tube as blank. Enzyme activity was expressed as mg of maltose (calculated from standard graph of maltose) produced per min.

\section{Total carotenoid and lycopene content:}

The experiments were determined by the method of Zakaria et al. (1979) (12) with slight modification. The $0.5 \mathrm{~g}$ sample was homogenized in a mortar pestle and then saponified with $3 \mathrm{ml}$ of $10 \%$ alcoholic potassium hydroxide in a water bath at $70^{\circ} \mathrm{C}$ for $30 \mathrm{~min}$. The extract was transferred in a separating funnel with $10 \mathrm{ml}$ petroleum ether and then mixed thoroughly. Then the upper layer containing carotenoids and lycopene was collected and lower layer was transferred in another separating funnel for further purification and repeat this step until the aqueous layer become colorless. For removing the extra moisture from petroleum ether extract added small amount of anhydrous sodium sulphate until effervescence disappear. The final volume was noted for further calculation. The absorbance of the assay mixture was measured at $450 \mathrm{~nm}$ and $503 \mathrm{~nm}$ for carotenoid and lycopene content respectively in a UV-VIS spectrophotometer (Cecil). Total carotenoid and lycopene content was determined using the following formulae:

$\begin{aligned} & \text { Amount of total } \\ & \text { carotenoids }\end{aligned}=\frac{\mathrm{A}_{450} \mathrm{X} \text { Volume of the sample } \times 100 \times 4}{\text { Weight of the sample }}$

Amount
lycopene of $=\frac{\mathrm{A}_{450} \times \text { Volume of the sample } \times 100 \times 3.12}{\text { Weight of the sample }}$

Amount of total carotenoids and lycopene content were expressed as $\mathrm{mg} / \mathrm{g}$ of the sample.

\section{Lipid Peroxidation:}

Determination of malondialdehyde was done from fresh plant sample according to R. L. Heath and L. Packer, 1968 (13) with some modification. 1g of plant sample homogenized in liquid nitrogen and extracted with $10 \%$ TCA containing $0.5 \%$ TBA followed by centrifugation at $12000 \mathrm{x}$ g for $15 \mathrm{~min}$ at $4^{\circ} \mathrm{C}$ temp. The extract was heated at $95^{\circ} \mathrm{C}$ for 30 min and the reaction was stopped by cooling in an ice bath. The absorbance of the contents was measured at $532 \mathrm{~nm}$ and $600 \mathrm{~nm}$ in a UV-VIS spectrophotometer (Cecil). MDA concentration was calculated by using following formula:
$\mathrm{A}_{532}-\mathrm{A}_{600}=\varepsilon \mathrm{CL}$
$\varepsilon=$ Extinction coefficient (155 is extinction coefficient of MDA)
$\mathrm{C}=$ Concentration
$\mathrm{L}=$ Path length (Distance of the cuvette $=1 \mathrm{~cm}$ )

\section{Protein Oxidation:}

Determination of carbonyl content was done by Dinitrophenyl hydragene (DNPH) reagent according to Foyer and Noctor (2005) (14). $1.0 \mathrm{~g}$ of fresh plant samples were homogenized in liquid nitrogen by addition of $10 \%$ (w/v) sodium dodecyl sulphate (SDS) incubating at room temperature for $20 \mathrm{~min} .10 \mathrm{mM}$ DNPH and $1.5 \mathrm{mM}$ TCA were added followed by gentle agitation. The pellet was suspended with $200 \mathrm{mM}$ sodium phosphate buffer (pH 7.0) and the absorbance was read at $360 \mathrm{~nm}$. The carbonylated derivative of protein was calculated using the molar extinction coefficient $\left(22000 \mathrm{M}^{-1} \mathrm{~cm}^{-1}\right)$ of DNPH.

\section{Superoxide $\left(\mathrm{O}_{2} \cdot\right)$ content:}

Generation of $\mathrm{O}_{2}$. content from treated plant samples were determined according to Elstner and Heupel (1976) (15). $1 \mathrm{~g}$ of plant tissue was homogenized in liquid nitrogen by adding $65 \mathrm{mM}$ phosphate buffer ( $\mathrm{pH}$ 7.8). The homogenate was centrifuged at $7000 \mathrm{~g}$ for $20 \mathrm{~min}$ at $4^{\circ} \mathrm{C}$. Thereafter, 
the supernatant was collected and added within 3 $\mathrm{ml}$ of assay mixture containing $65 \mathrm{mM}$ phosphate buffer, $10 \mathrm{mM}$ hydroxyl-amine and supernatant. The reaction was incubated for $30 \mathrm{~min}$ at $25^{\circ} \mathrm{C}$. Thereafter, $10 \mathrm{mM}$ sulphanilamide and $7 \mathrm{mM}$ anapthyl amine were added and incubated for 20 min at room temp. The absorbance was read at $530 \mathrm{~nm}$ and the concentration of $\mathrm{O}_{2} \cdot{ }^{-}$was derived by using $\mathrm{NO}_{2}^{-}$as standard.

\section{Hydrogen peroxide $\left(\mathrm{H}_{2} \mathrm{O}_{2}\right)$ content:}

$\mathrm{H}_{2} \mathrm{O}_{2}$ content of treated plants was done according to Ghosh et al. (2011) (16). $500 \mathrm{mg}$ of plant tissue was homogenized in liquid nitrogen by adding 2 $\mathrm{ml}$ of $1 \%(\mathrm{w} / \mathrm{v})$ trichloro acetic acid (TCA). The homogenate was centrifuged at 10,000 $\mathrm{g}$ for $15 \mathrm{~min}$ at $4^{\circ} \mathrm{C}$. Thereafter, the supernatant was collected and added within assay mixture containing $10 \mathrm{mM}$ potassium phosphate buffer $(\mathrm{pH} 7)$ and $1 \mathrm{mM}$ potassium iodide (KI) followed by incubation in dark for $20 \mathrm{~min}$. The absorbance was read at 390 $\mathrm{nm}$. The $\mathrm{H}_{2} \mathrm{O}_{2}$ content was derived using a standard solution.

\section{Superoxide dismutase activity:}

SOD activity was done Cakmak and Marschner (1992) (17) by measuring the ability to inhibit the photochemical reduction of nitro blue tetrazolium. The fresh plant samples were homogenized within liquid N2 and extracted using the extraction buffer containing $100 \mathrm{mM}$ phosphate buffer $(\mathrm{pH}=7.0)$, $100 \mathrm{mM}$ EDTA, $10 \mathrm{mM}$ PMSF, $10 \mathrm{mM} \mathrm{MgCl} 2,10 \mathrm{mM} \beta-$ ME and 4\% PVP. The assay mixture containing $100 \mathrm{mM}$ phosphate buffer $(\mathrm{pH}=7.0), 10 \mathrm{mM}$ methionine, $75 \mathrm{mM}$ NBT, $100 \mathrm{mM}$ EDTA and $100 \mu \mathrm{l}$ enzyme extract. The reaction was started after addition of $2 \mu \mathrm{M}$ riboflavin and thereafter the experimental tubes were illuminated under $20 \mathrm{~W}$ fluorescent lights for $15 \mathrm{~min}$. The absorbances of the illuminated tubes were measured at $560 \mathrm{~nm}$. The SOD activity was expressed as Unit/mg of protein.

\section{Guaiacol peroxidase activity:}

Peroxidase activity was determined by the oxidation of guaiacol according to Verma and Dubey (2003) (18). The reaction was started with a $3 \mathrm{ml}$ reaction mixture containing $100 \mathrm{mM}$ phosphate buffer ( $\mathrm{pH}=7.5), 10 \mathrm{mM}$ guaiacol, $200 \mu \mathrm{l}$ enzyme extract and $2 \mathrm{mM} \mathrm{H}_{2} \mathrm{O}_{2}$. The activity was measured at $470 \mathrm{~nm}$ at $30 \mathrm{sec}$ intervals to determine the change in absorbance 0.1 and specific activity of enzyme was expressed as unit/gm f.wt.

\section{Catalase activity:}

CAT activity was done according to Verma and Dubey (2003) (18). The enzyme was extracted within liquid $\mathrm{N}_{2}$ using the above-mentioned extraction buffer in a prechilled mortar and pestle.
The reaction mixture containing $200 \mathrm{mM}$ potassium phosphate buffer $(\mathrm{pH}=7)$ and $10 \mathrm{mM}$ $\mathrm{H}_{2} \mathrm{O}_{2}$. The reaction was started by adding $200 \mu \mathrm{l}$ of enzyme extract and the decrease in absorbance was recorded at $240 \mathrm{~nm}$ per min and activity was detected using the extinction coefficient of $39.4 \mathrm{M}$ $1 \mathrm{~cm}^{-1}$ for $\mathrm{H}_{2} \mathrm{O}_{2}$.

\section{Glutathione Reductase activity:}

GR activity was done by determining the glutathione dependent oxidation of $\mathrm{NAD}(\mathrm{P}) \mathrm{H}$ according to Cakmak and Marschner (1992) (17). The enzyme was extracted using the abovementioned extraction buffer. The assay mixture containing $100 \mathrm{mM}$ phosphate buffer $(\mathrm{pH}=7.5)$, $5 \mathrm{mM}$ EDTA, 2mM NAD(P)H, $30 \mathrm{mM}$ oxidized glutathione. The reaction was started by the addition of $200 \mu \mathrm{l}$ enzyme extract and the decrease in absorbance was recorded at 340 $\mathrm{nm}$ for $2 \mathrm{~min}$. The activity was calculated using molar extinction coefficient for $\mathrm{NAD}(\mathrm{P}) \mathrm{H}$ of $6.22 \mathrm{mM}^{-1} \mathrm{~cm}^{-1}$ and expressed as $\mathrm{nM}$ NAD(P)H oxidized $\mathrm{min}^{-1} \mathrm{mg}^{-1}$ of protein.

\section{Statistical analysis:}

The data obtained were statistically tested with ANOVA using the general linear model. The variations between the means of treatments with three replications were compared using Duncan's multiple range tests (at $P \leq 0.05$ ).

\section{Results}

The results of the present experiment are focused with the most possible changes of SUB1 trait when there is a transit from submergence to desubmergence. Rice varieties under submerged condition, particularly, for those of tolerant cultivars are displayed with two strategies: either quiescence or elongation ability. Whatever of those, when the varieties are transfer from submergence to aerated condition the plant might resume its normal growth through aerobic respiration (19). In the present experiment, it is of those cellular responses expressed under sudden transit from hypoxic/anoxic to aerobic condition are embedded herein. Moreover, the responses are under regulation of two chemical elicitors, PA and SA with the standard dose to check any influence on cellular responses. PA and SA have quite been deciphered mostly with water, salinity, oxidative stress than that of flooding or submergence stress.

Initially the Swarna Sub1A was marked with a significant variation in total carbohydrate content under 5 days of complete submergence followed by 1-day de-submergence to recover. Swarna Sub1A maintain $36.66 \%$ down-regulation to accumulate to total carbohydrate in its culm and leaf sheath in case of submergence as compared to control which again under gone recovery by 1.31fold and 1.26-fold by PA and SA respectively (Fig. 1). In support of carbohydrate accumulation 


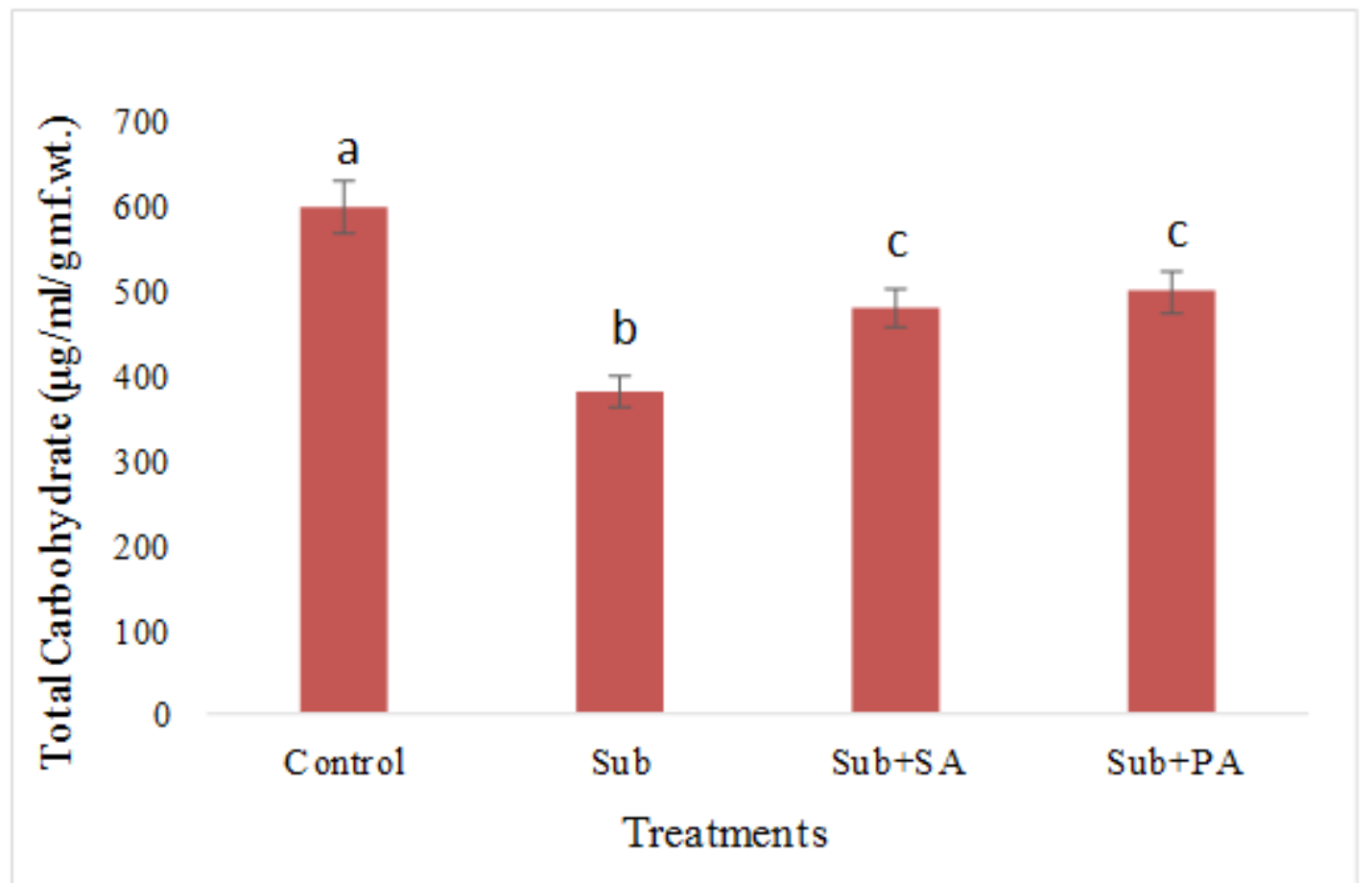

Fig. 1: Assay of total carbohydrate content in Swarna Sub1A under Normal (control), Submerged, Submerged+Salicylic acid $(1 \mathrm{mM})$ and Submerged+Putrescine $(2 \mathrm{mM})$ treatment for 5 days. Data represented as mean of three replicates $(n=3) \pm S E$. SE is represented as vertical bar on each column. Bars showing different letters indicate significant differences according to Duncan's test at $\mathrm{p}<0.05$.

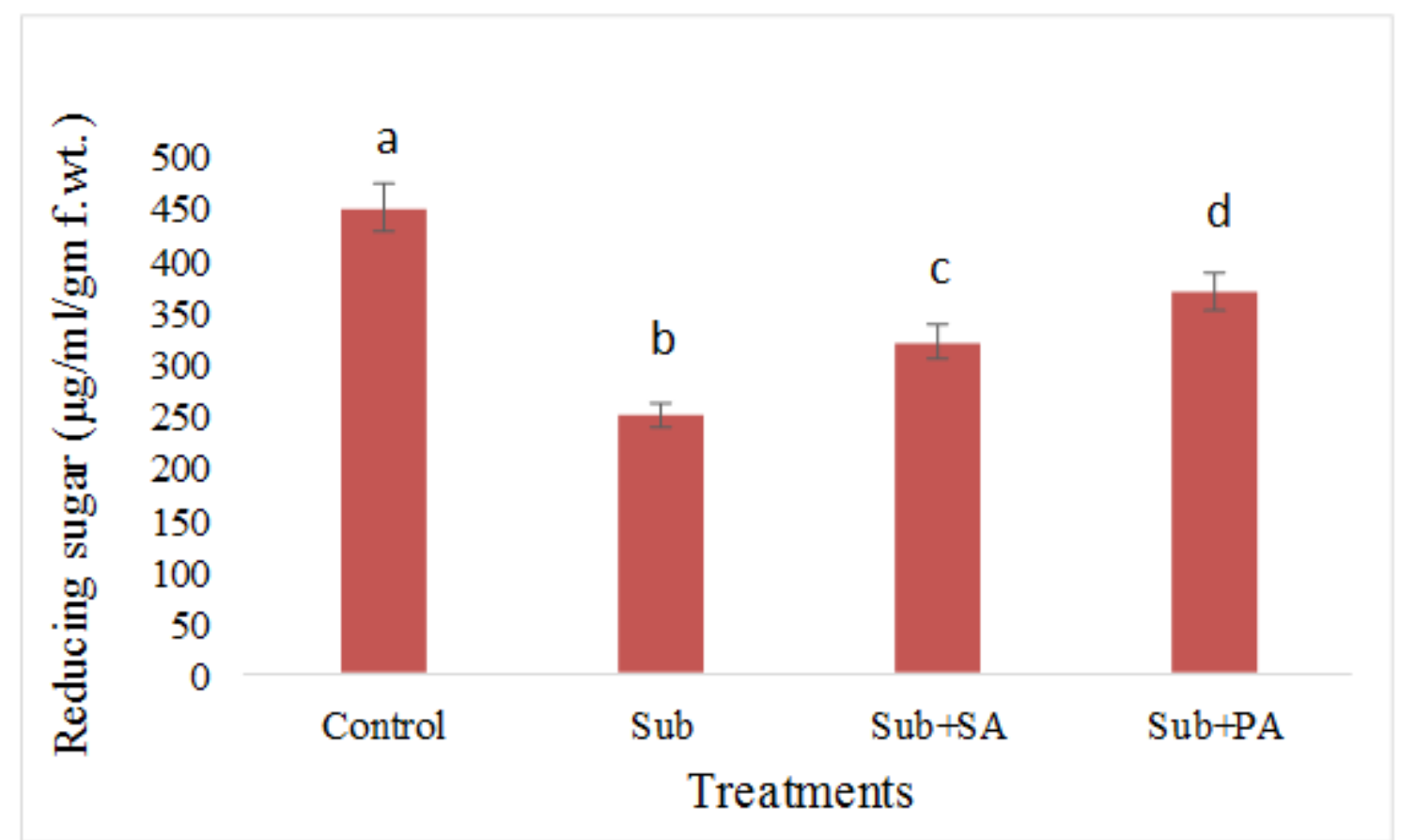

Fig. 2: Assay of reducing sugar content in Swarna Sub1A under Normal (control), Submerged, Submerged+Salicylic acid $(1 \mathrm{mM})$ and Submerged+Putrescine $(2 \mathrm{mM})$ treatment for 5 days. Data represented as mean of three replicates $(n=3) \pm$ SE. SE is represented as vertical bar on each column. Bars showing different letters indicate significant differences according to Duncan's test at $\mathrm{p}<0.05$.

through current photosynthesis the soluble sugar, mostly the reducing sugar as photosynthates were also consistent to justify the plant responses. The decline in reducing sugar was significant $(\mathrm{P} \leq 0.05)$ by $44.44 \%$ which denotes solubilization of total carbohydrate including non-structural residues were under controls. The strategy to regulate the expense of soluble sugar is quite expected from
SUB1 locus and that also moderated by PA (1.48 fold) and SA (1.28 fold) (Fig. 2). Activity of $a-$ amylase is often contextual in description of SUB1 possessing allele rice land races. Questions still there whether this locus is realized in quiescence strategies either through constitutive or inductive expressions? For the later, it becomes more prudent that stringency is prevent in release of 


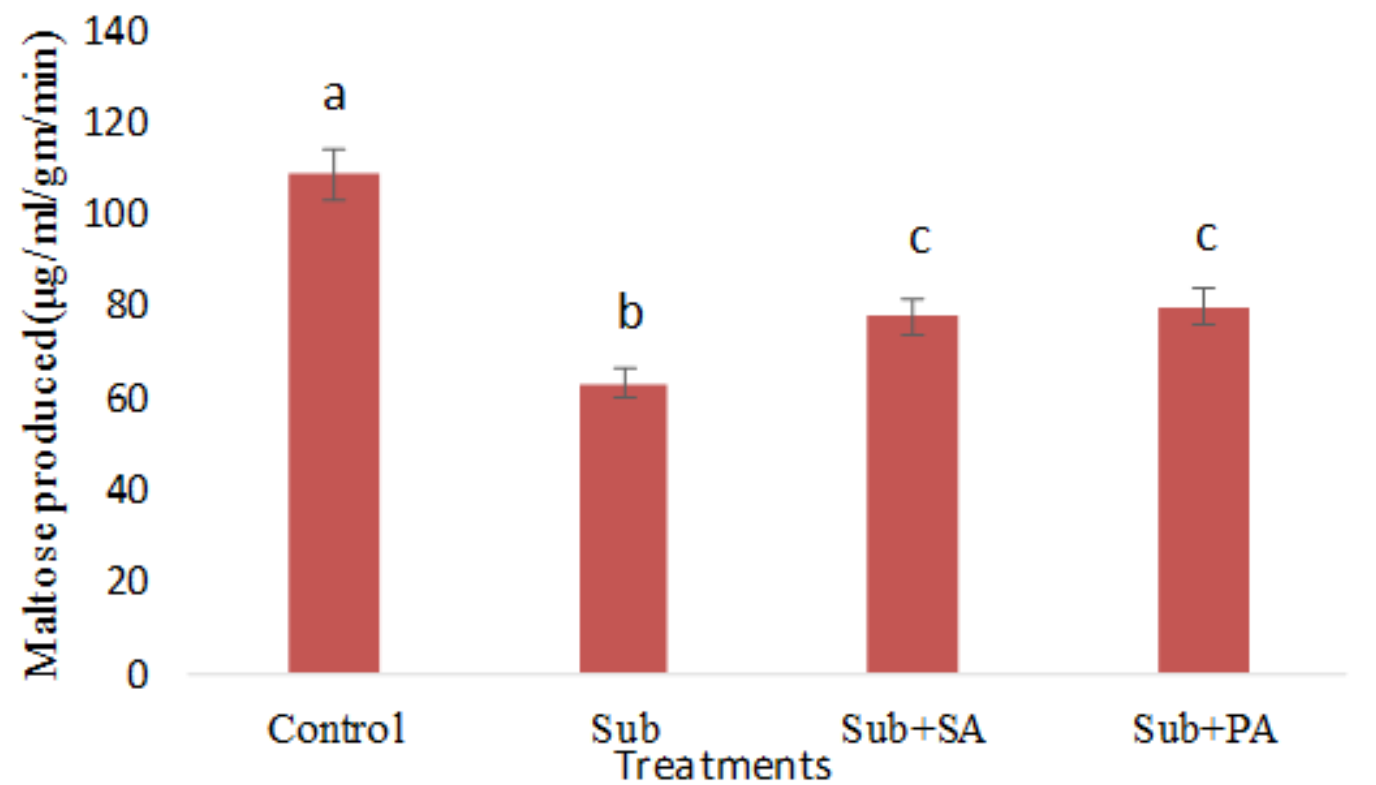

Fig. 3: Assay of a-amylase activity in Swarna Sub1A under Normal (control), Submerged, Submerged+Salicylic acid $(1 \mathrm{mM})$ and Submerged+Putrescine $(2 \mathrm{mM})$ treatment for 5 days. Data represented as mean of three replicates $(\mathrm{n}=3)$ \pm SE. SE is represented as vertical bar on each column. Bars showing different letters indicate significant differences according to Duncan's test at $\mathrm{p}<0.05$.

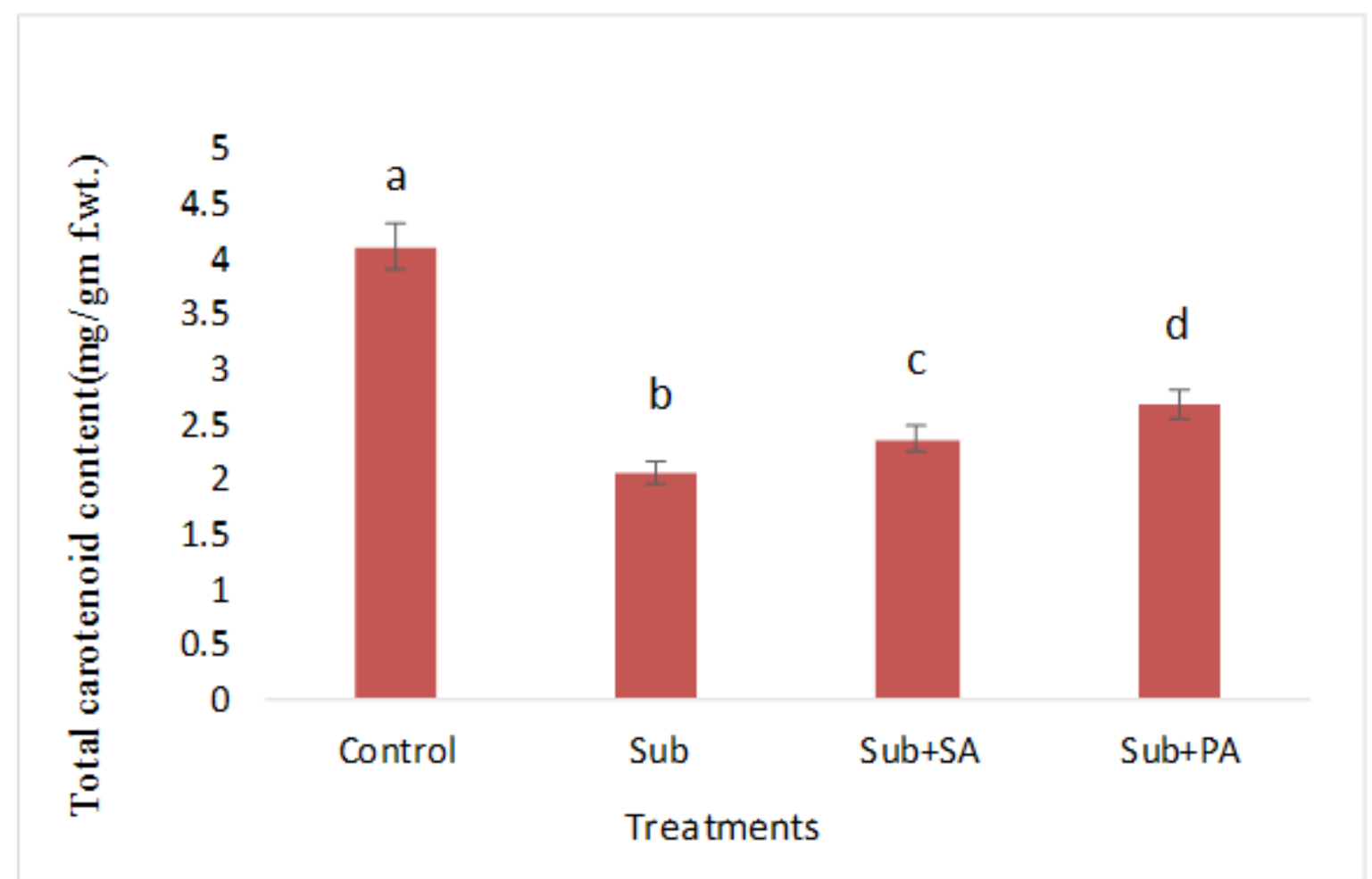

Fig. 4: Assay of total carotenoid content in Swarna Sub1A under Normal (control), Submerged, Submerged+Salicylic acid $(1 \mathrm{mM})$ and Submerged+Putrescine $(2 \mathrm{mM})$ treatment for 5 days. Data represented as mean of three replicates $(n=3) \pm S E$. SE is represented as vertical bar on each column. Bars showing different letters indicate significant differences according to Duncan's test at $\mathrm{p}<0.05$.

soluble sugars for developing culm and leaf sheath under hypoxic/anoxic condition of submergence. Fig. 3 establish this fact by a significant downregulation of a-amylase activity by $42.27 \%$ over control. However, both PA and SA have recover some effect on submerged tissues by $1.26 \& 1.23-$ fold (Fig. 3) respectively in enzyme activity compared to submerged plants but was not significant between themselves $(\mathrm{P} \leq 0.05)$. Still, the effect of these elicitors may be understood as moderation of SUB1 to resume the activities in support of plant growth and development in a 


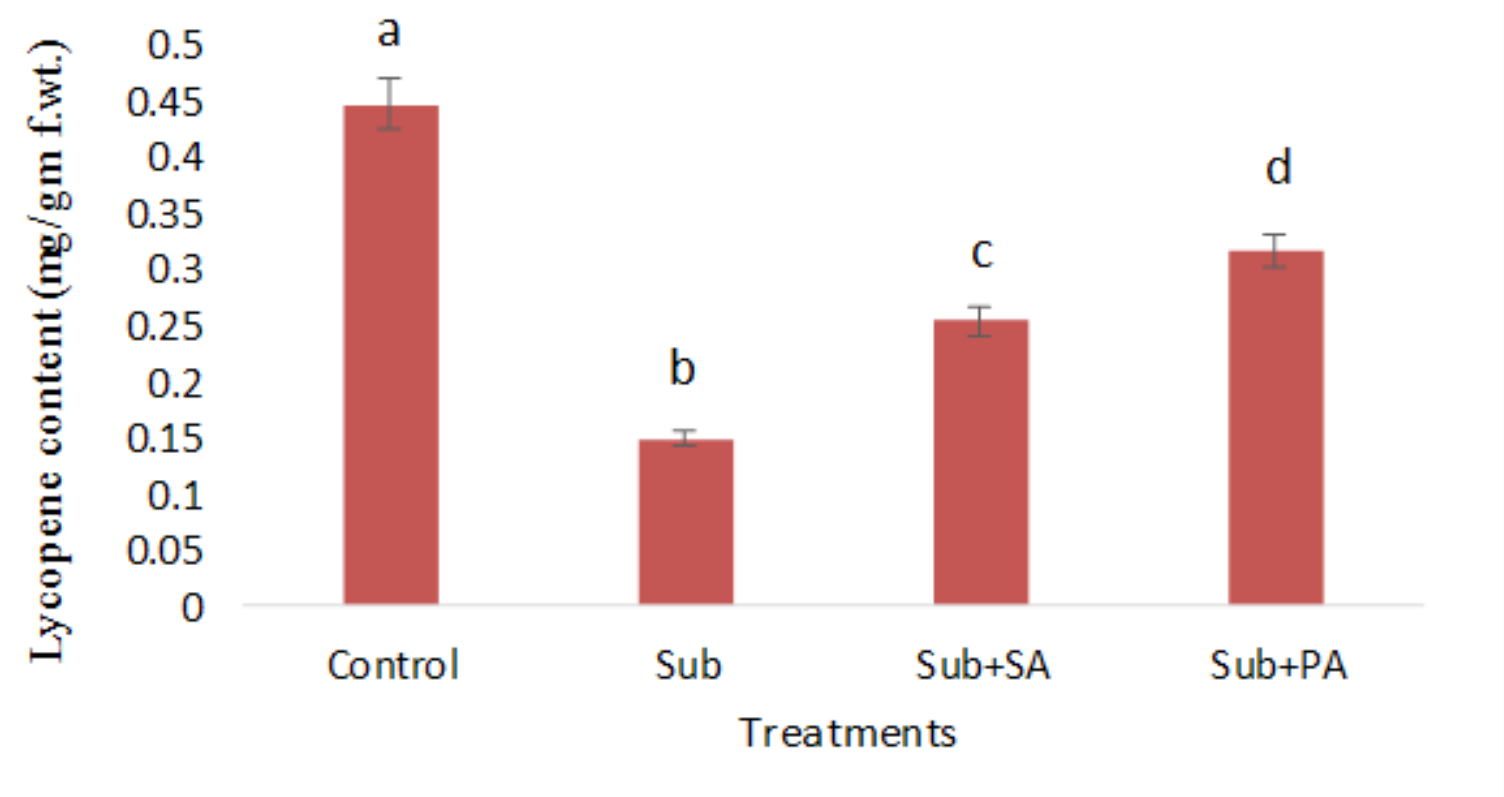

Fig. 5: Assay of lycopene content in Swarna Sub1A under Normal (control), Submerged, Submerged+Salicylic acid $(1 \mathrm{mM})$ and Submerged+Putrescine $(2 \mathrm{mM})$ treatment for 5 days. Data represented as mean of three replicates $(\mathrm{n}=3)$ \pm SE. SE is represented as vertical bar on each column. Bars showing different letters indicate significant differences according to Duncan's test at $\mathrm{p}<0.05$.

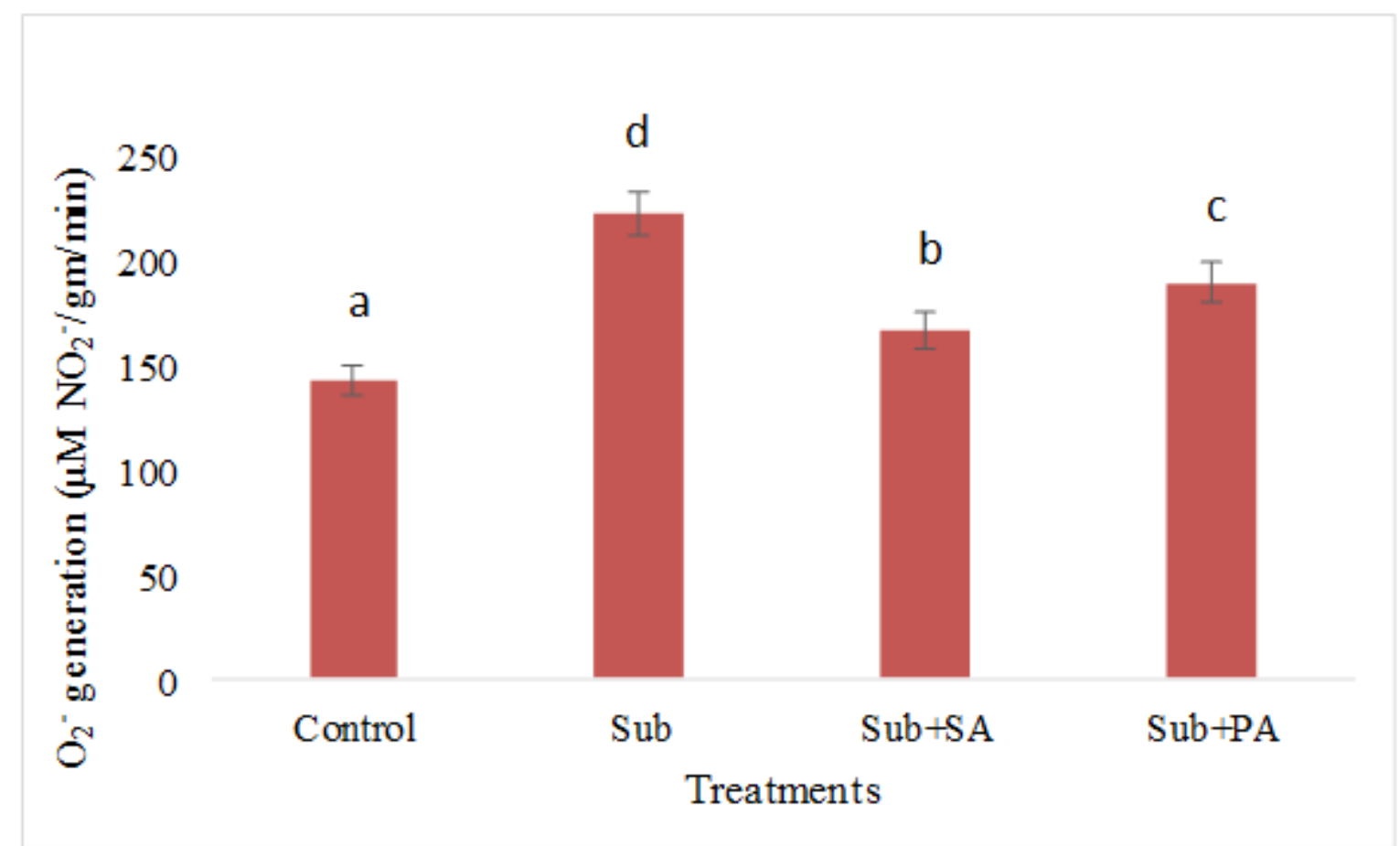

Fig. 6: Assay of $\mathrm{O}_{2}$. generation in Swarna Sub1A under Normal (control), Submerged, Submerged+Salicylic acid $(1 \mathrm{mM})$ and Submerged+Putrescine $(2 \mathrm{mM})$ treatment for 5 days. Data represented as mean of three replicates $(\mathrm{n}=3)$ \pm SE. SE is represented as vertical bar on each column. Bars showing different letters indicate significant differences according to Duncan's test at $\mathrm{p}<0.05$.

more non-significant manner. The important photosynthetic pigments like carotenoid and lycopene which helps the plant to recover photooxidative damages caused by different stressors. In the present experiment, total carotenoid and lycopene contents are being down-regulated by $50.00 \%$ and $66.59 \%$ respectively over control but when PA and SA are treated, the total carotenoid and lycopene content over up-regulated by 1.30 \& 2.12-fold and $1.14 \& 1.70$-fold respectively as compared to submerged plants (Fig. 4 \& 5).

The most critical factor set with sustainability under submergence of plant is a transient oxygenic burst while water level recedes. 


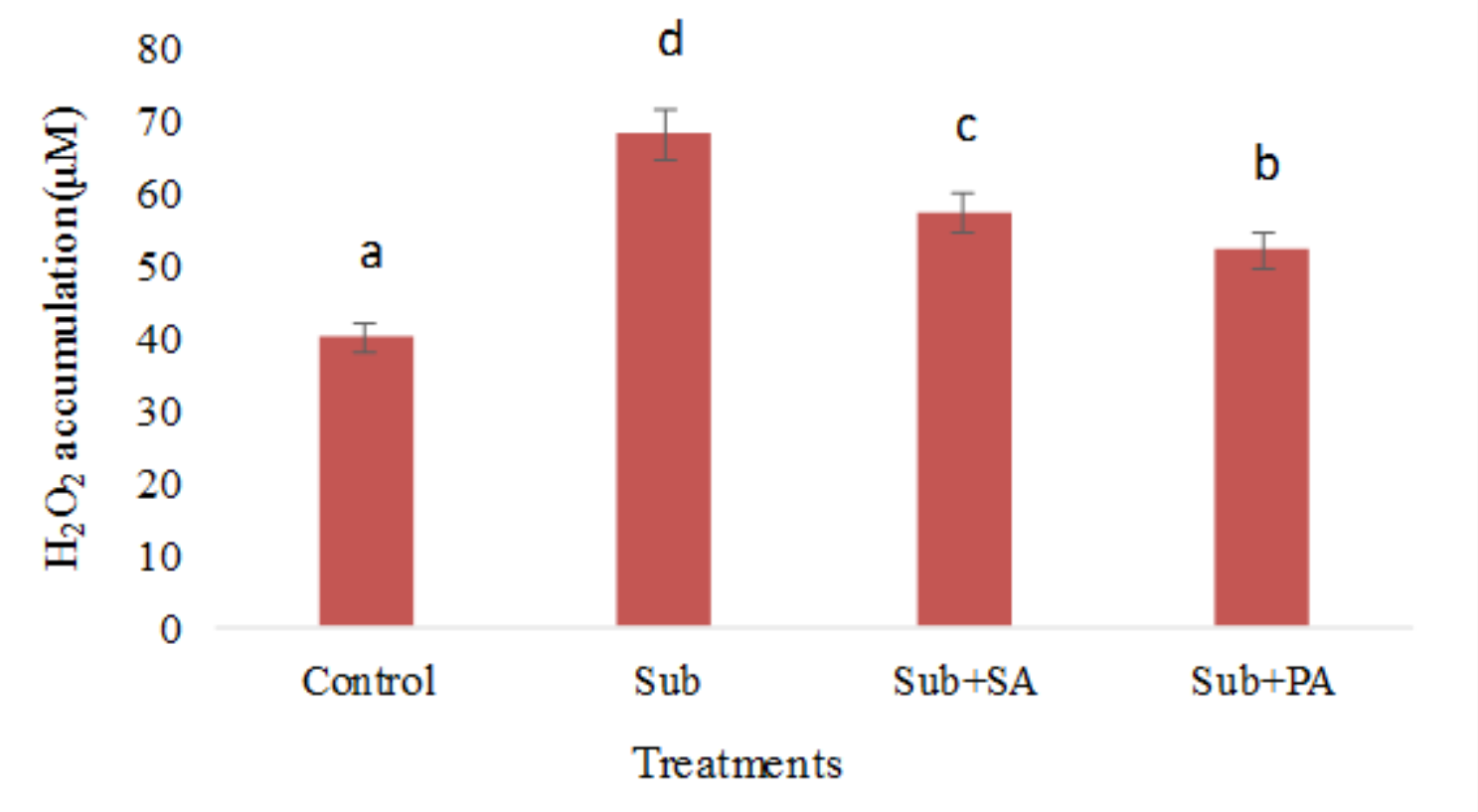

Fig. 7: Assay of $\mathrm{H}_{2} \mathrm{O}_{2}$ accumulation in Swarna Sub1A under Normal (control), Submerged, Submerged+Salicylic acid $(1 \mathrm{mM})$ and Submerged+Putrescine $(2 \mathrm{mM})$ treatment for 5 days. Data represented as mean of three replicates $(\mathrm{n}=3)$ \pm SE. SE is represented as vertical bar on each column. Bars showing different letters indicate significant differences according to Duncan's test at $\mathrm{p}<0.05$.

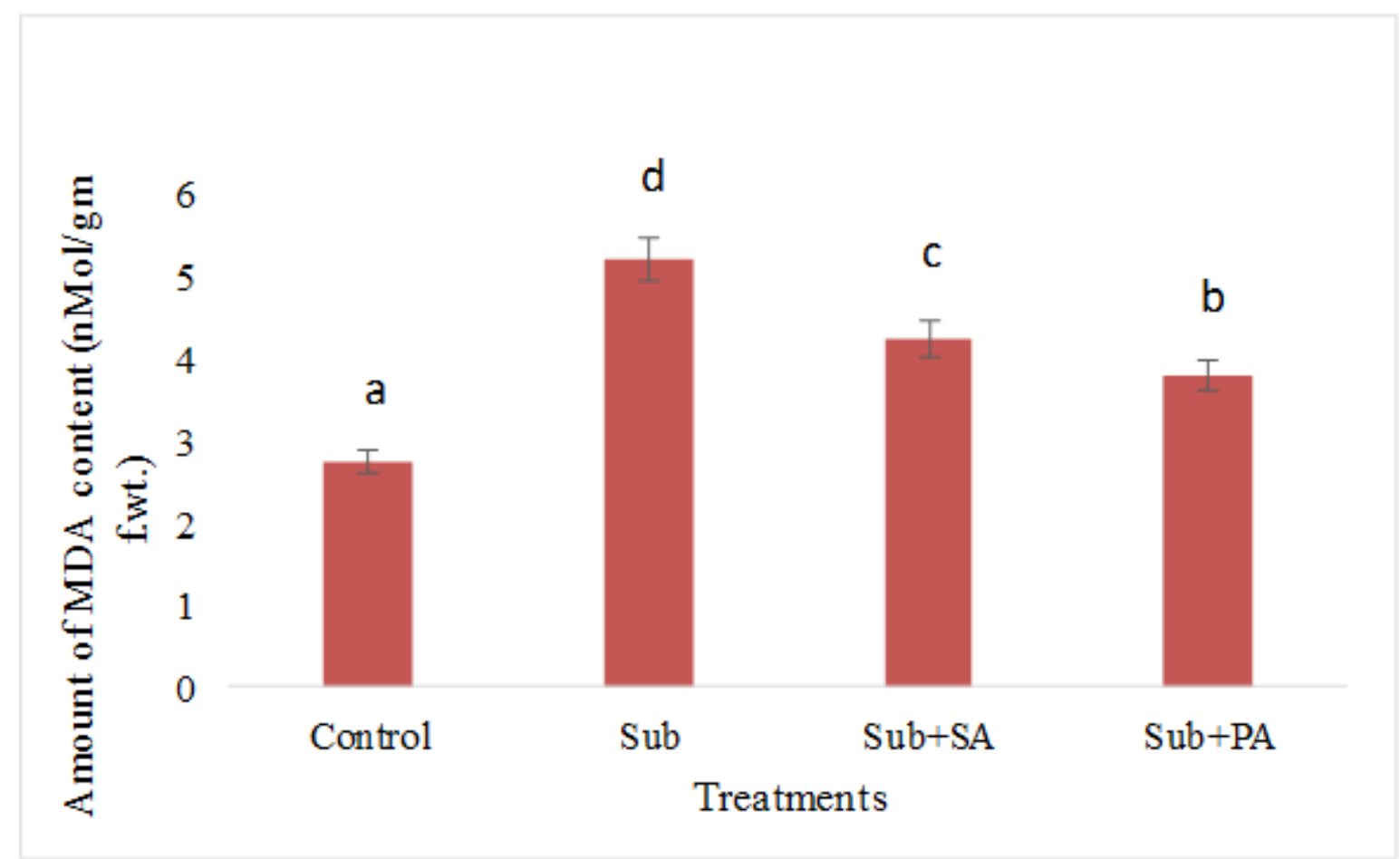

Fig. 8: Assay of MDA content in Swarna Sub1A under Normal (control), Submerged, Submerged+Salicylic acid (1mM) and Submerged+Putrescine $(2 \mathrm{mM})$ treatment for 5 days. Data represented as mean of three replicates $(n=3) \pm S E$. SE is represented as vertical bar on each column. Bars showing different letters indicate significant differences according to Duncan's test at $\mathrm{p}<0.05$.

In most of the cases the tolerant land races are quite stable under submergence while that goes in vulnerability when comes up de-submergence. The changes of redox were markedly observed in the present experiment when c.v. Swarna Sub1A accumulated a significant amount of ROS (Fig. 6 \&
7). However, it is the merit of SUB1 QTL that it overcomes the consequences of ROS through cellular degeneration of bio-molecules. Thus, when plant accumulated 1.55-fold over expression of apoplastic superoxide $\left.\left(\mathrm{O}_{2} \cdot\right)^{-}\right)$a concomitant induction of lipid peroxidation (1.91-fold) was the 


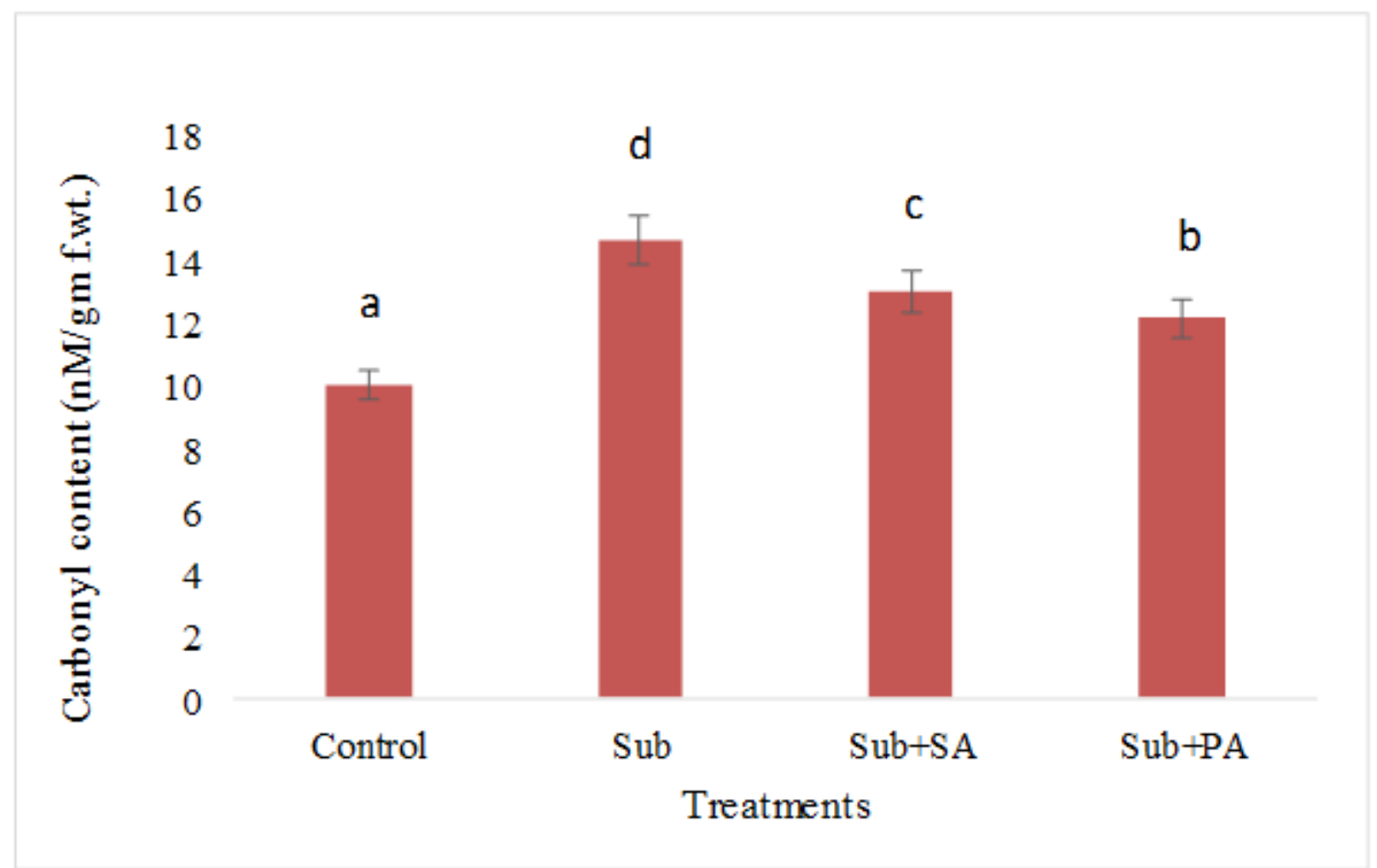

Fig. 9: Assay of carbonyl content in Swarna Sub1A under Normal (control), Submerged, Submerged+Salicylic acid $(1 \mathrm{mM})$ and Submerged+Putrescine $(2 \mathrm{mM})$ treatment for 5 days. Data represented as mean of three replicates $(\mathrm{n}=3)$ \pm SE. SE is represented as vertical bar on each column. Bars showing different letters indicate significant differences according to Duncan's test at $\mathrm{p}<0.05$.

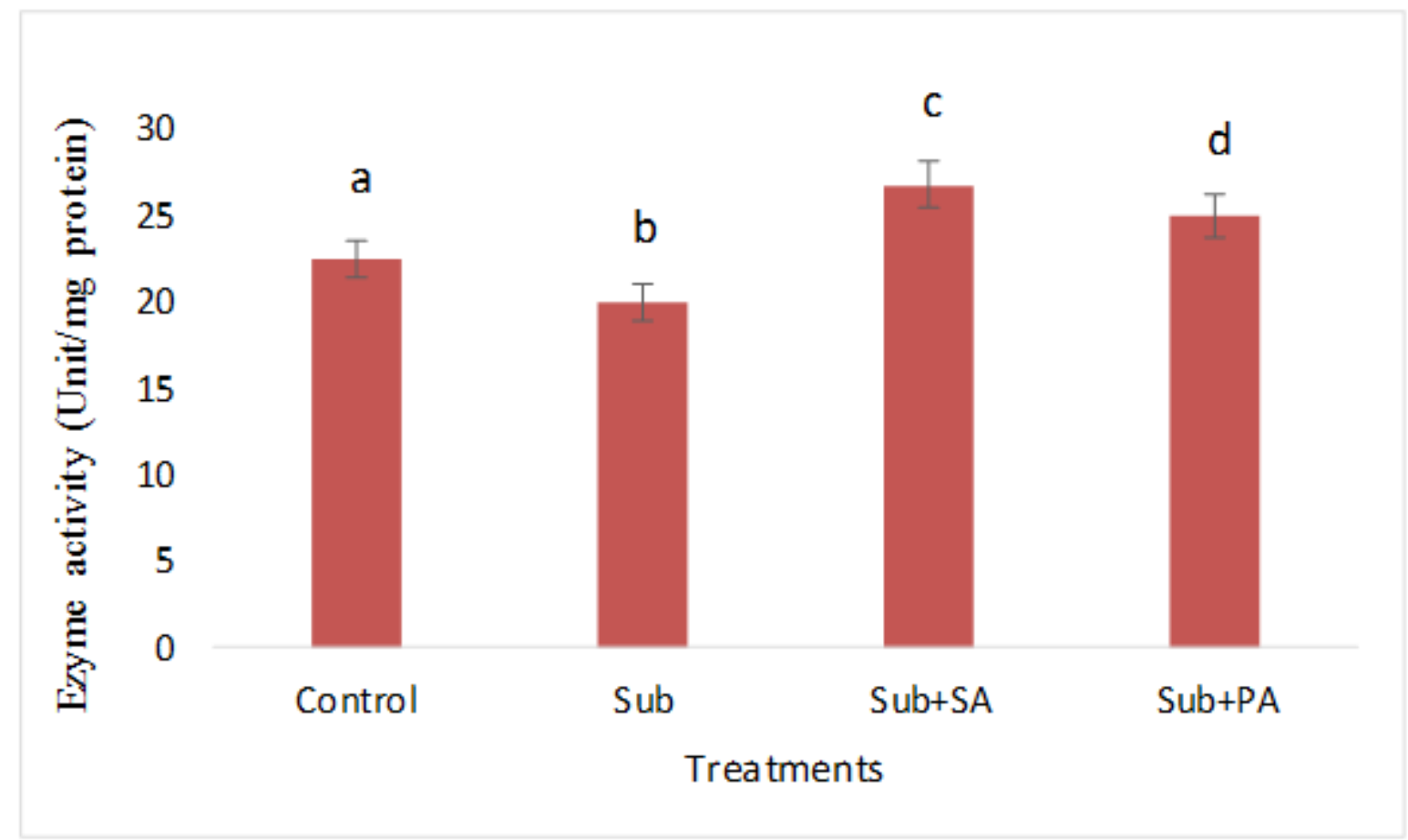

Fig. 10: Assay of SOD activity in Swarna Sub1A under Normal (control), Submerged, Submerged+Salicylic acid (1mM) and Submerged+Putrescine $(2 \mathrm{mM})$ treatment for 5 days. Data represented as mean of three replicates $(n=3) \pm S E$. SE is represented as vertical bar on each column. Bars showing different letters indicate significant differences according to Duncan's test at $\mathrm{p}<0.05$.

result (Fig. $6 \&$ 8). At significant level $(\mathrm{P} \leq 0.05)$, the amount of peroxides by ROS induced reactions characterize the oxidative stress. $\mathrm{H}_{2} \mathrm{O}_{2}$, another ROS however, not a free radical realized the similar trend in their accumulation (1.70-fold than control) in rice varieties (Fig. 7). The product of
$\mathrm{H}_{2} \mathrm{O}_{2}$ mediated protein-carbonylation was also accompanied with lipid peroxide by 1.46 -fold and also support the oxidative stress under desubmergence. But both PA and SA at the compatibility to moderate level, down-regulate the $\mathrm{O}_{2}$ - generation ( $14.80 \%$ \& $25.11 \%$ respectively) and 


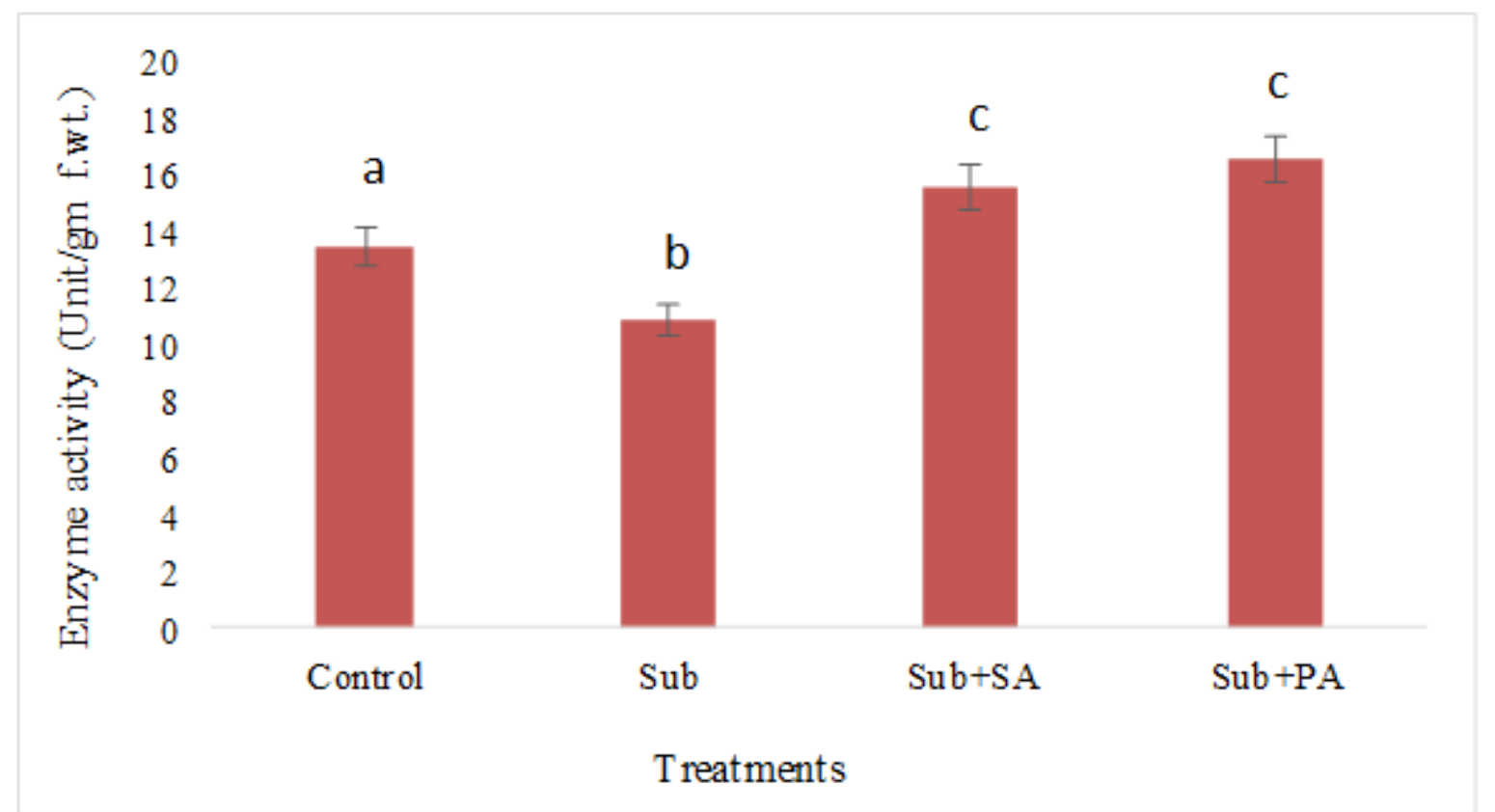

Fig. 11: Assay of GPX activity in Swarna Sub1A under Normal (control), Submerged, Submerged+Salicylic acid (1mM) and Submerged+Putrescine $(2 \mathrm{mM})$ treatment for 5 days. Data represented as mean of three replicates $(n=3) \pm S E$. SE is represented as vertical bar on each column. Bars showing different letters indicate significant differences according to Duncan's test at $\mathrm{p}<0.05$.

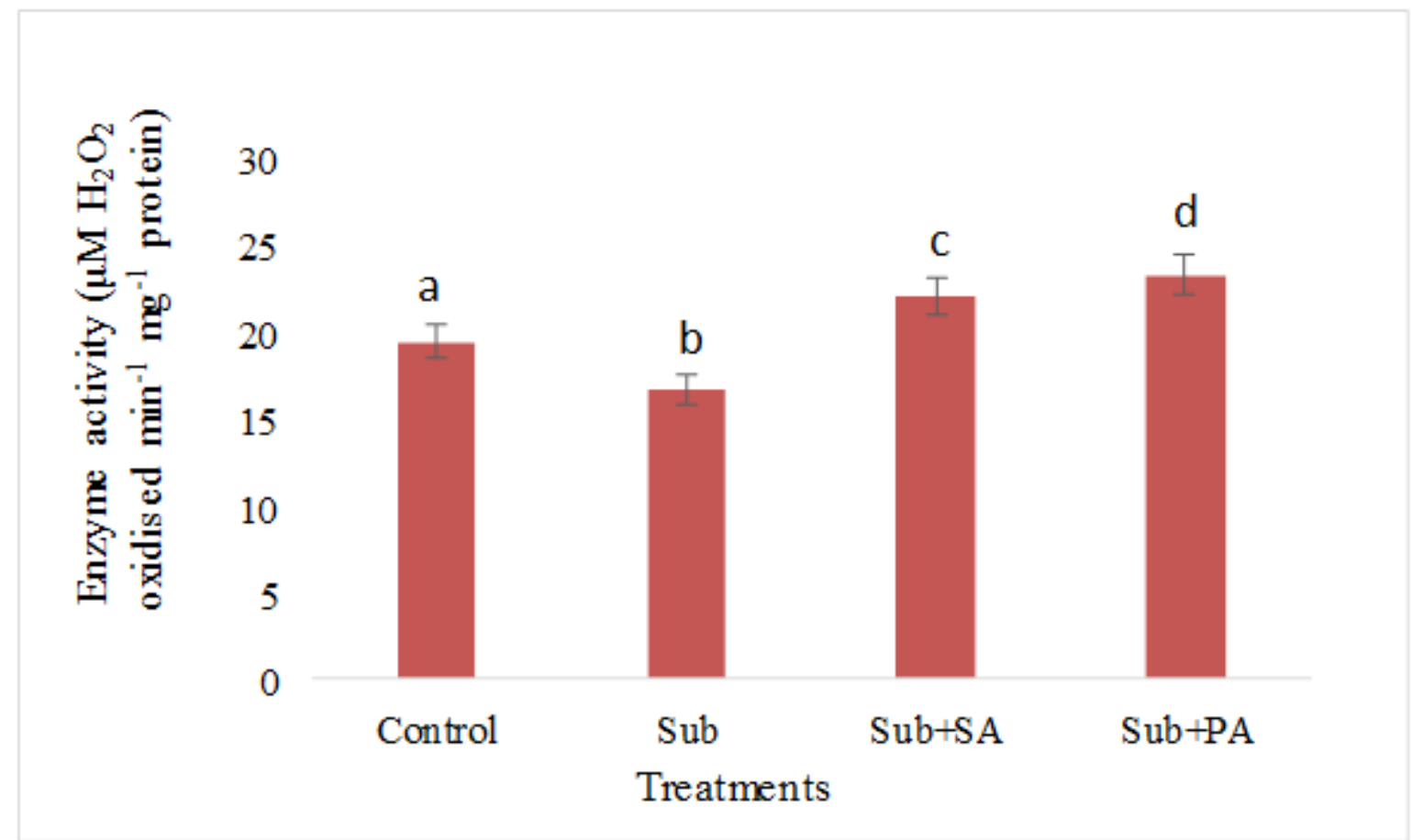

Fig. 12: Assay of CAT activity in Swarna Sub1A under Normal (control), Submerged, Submerged+Salicylic acid (1mM) and Submerged+Putrescine $(2 \mathrm{mM})$ treatment for 5 days. Data represented as mean of three replicates $(n=3) \pm S E$. SE is represented as vertical bar on each column. Bars showing different letters indicate significant differences according to Duncan's test at $\mathrm{p}<0.05$.

$\mathrm{H}_{2} \mathrm{O}_{2}$ generation (23.53\% \& $16.17 \%$ respectively) in a significant manner to sustain oxidative stress (Fig. 6 \& 7). Regardless of these two, the relief of macromolecule oxidation was satisfactory for MDA (Malondialdehyde) and carbonylated derivatives by the $27.58 \%, 18.77 \%$ \& $17.03 \%$, $11.44 \%$ respectively by PA and SA (Fig. $8 \& 9$ ).

The chemical messengers as PA and SA are supposed to be good reliever of the oxidative stress of Swarna Sub1A is evident from anti-oxidative enzyme activities. SOD is the first line of defense to ROS lyses the $\mathrm{O}_{2}$. into $\mathrm{H}_{2} \mathrm{O}_{2}$. Thereby, the elevated activity as recorded in present experiment undoubtedly scores the plant potential to tolerance. Thus, PA and SA mediation activities are modulated by upregulation with 1.25-fold and 1.34-fold respectively (Fig. 10). Development of the peroxide and its downstream effect is another criterion for oxidative stress from the tissue 


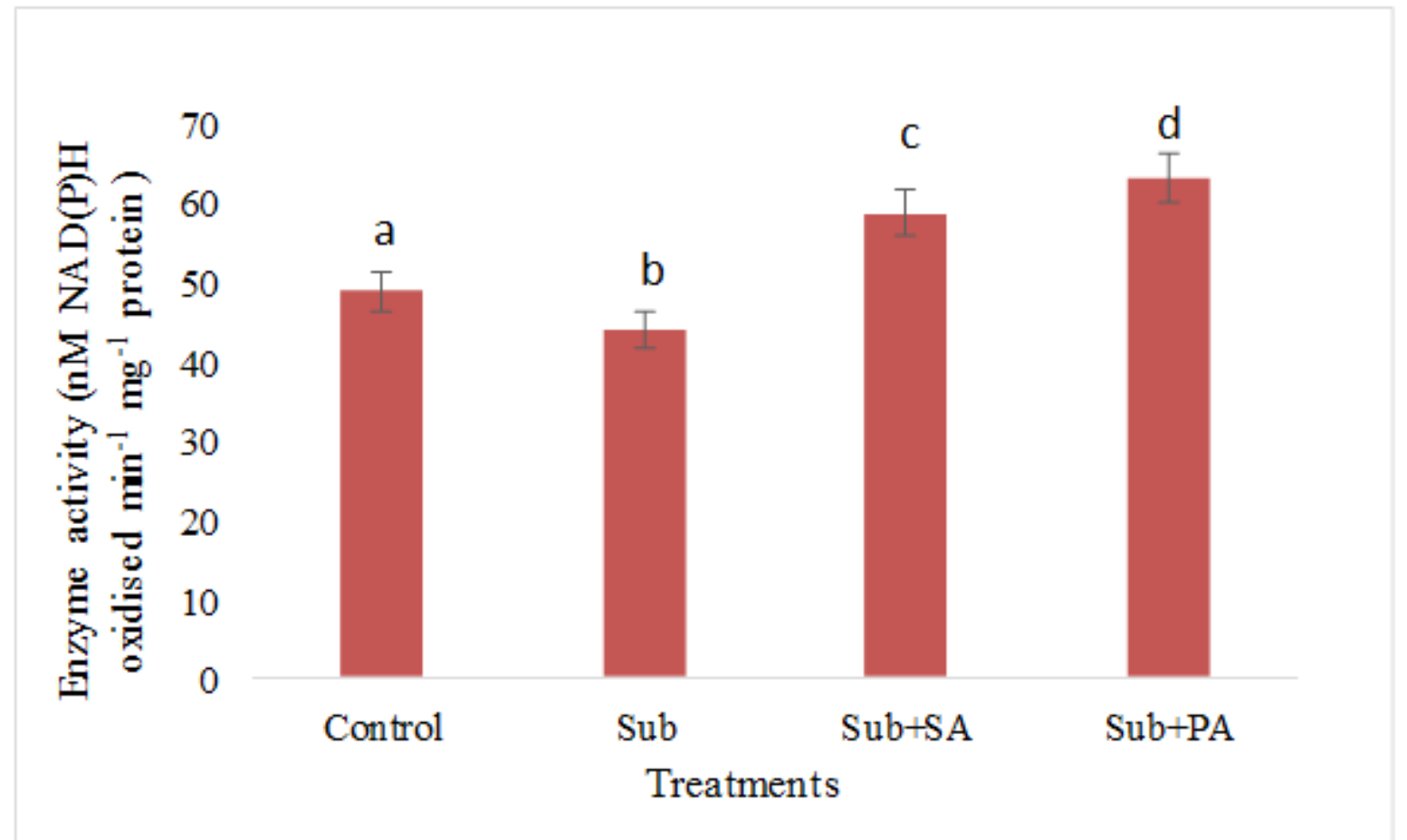

Fig. 13: Assay of GR activity in Swarna Sub1A under Normal (control), Submerged, Submerged+Salicylic acid (1mM) and Submerged+Putrescine $(2 \mathrm{mM})$ treatment for 5 days. Data represented as mean of three replicates $(n=3) \pm S E$. SE is represented as vertical bar on each column. Bars showing different letters indicate significant differences according to Duncan's test at $\mathrm{p}<0.05$.

extract the soluble peroxidase was recovered and in guaiacol mediated reaction it was recorded some discriminatory results. Submergence had not scored any significant changes in GPX activity. Thus, shows the sensitivity to ROS development under submergence (Fig. 11). However, two elicitors PA and SA were not much variable in there over expression between them, still 1.52-fold and 1.43-fold over expression as compared to submergence was distinguishing. The validity of nature for both PA and SA was also reflected when catalase (CAT) activity was concern. Plants responded in lysis of $\mathrm{H}_{2} \mathrm{O}_{2}$ by catalase was not promising under submergence. The escape from ROS as stress was also evident for CAT when PA and SA were registered. The degrees of changes in CAT activity were record by 1.39 -fold and 1.31 -fold for PA and SA (Fig. 12). On the contrary, the maintenance of redox in terms of glutathione metabolism was most striking in the present experiment. The fall of glutathione was evident under submergence by $10.03 \%$ as compared to control but recovered by PA and SA in the order of 1.44-fold and 1.33-fold respectively (Fig. 13).

\section{Discussion}

From the background of submergence sensitivity of rice plant, two major adaptations are observed: tolerance to water stress under submergence and reduction of oxidative damages of desubmergence/aeriation (20). However, irrespective of rice varieties prone to submergence either quiescence or escape strategies are followed. Swarna Sub1A, the present experimental material is well understood with its quiescence strategy where ethylene mediates suppression of stem elongation factors is the key factor. Thus, either degradation of bioactive gibberellins (GA) or its down-regulation of synthesis or both may be expected. Therefore, a suppression of growth is the result and that must be affected through different physiological components. In the present study, few related physiological responses are highlighted which could emphasize the different induced cellular anomaly under submergence. Initially, the suppression of the growth which is related to utilization of total photosynthates (carbohydrates) under water is much effected. A significant falling of total carbohydrate was documented as compared to control during 5 days submergence. All the replicate sets of the variety scored their maximum tolerance within 5 days (data not presented herein). Interestingly PA and SA were quite satisfactory to relive the loss of total carbohydrates as compared to submergence. The efficiency of PA and SA more likely are related to increase the stomatal conductance for $\mathrm{CO}_{2}$ and down-stream conversion into carbohydrates. Moreover, the induction of membrane permeability to induce the PA to reach the reaction center of photosystem to shield against developing ROS has been documented and thereby, retention of photosynthetic activities. PA and SA, both owing to their negative charge domain may be a shielding capacity over the positively charged membrane and other macro-molecules (21). The roles of these elicitors have almost a similar promotive effect when alpha-amylase activity was recorded. In quiescence strategy of plants, 
particularly, the rice varieties having SUB1 allele are characterized to induce ethylene for downregulation of few genes, a-amylase being the predominant of those (22). Undoubtedly, less exhaustion of carbohydrates through solubilization for respiratory flask is the prime determinant for quiescence strategy. PA and SA are substantially complemented to induce anaerobic metabolism by over expressed amylase activity as found in present experiment. This is quite corroborated with a consumption of carbon most efficiently under submergence in SUB1 possessing variety (23). The enrichment of photosynthetic activation as good as nonsubmerged conditions and its sustainability may be another factor for submergence tolerant line. Swarna Sub1A is no exception of this where the synthesis of accessory pigments like carotenoid and lycopene with chlorophyll were maximally bothered. Therefore, alternative pigment system must be approachable to protect the loss of carotenoids and lycopene in a way that photo oxidation might be moderated (24). In present experiment, PA and SA are most approachable to sustain both the pigments, however, not comparable but compatible to control plants.

In the second module of submergence stress rice plants are very often encounter with an elevated oxygen tension ensuring the oxidative stress. Development of the ROS occurs, particularly, when the tissues are under desubmergence with a high oxygen partial pressure complemented with high irradiance. Multiple changes in tissues integrity and function are the results of such oxidative stress (25). In the present experiment, the accumulation of ROS in the form of $\mathrm{O}_{2}$. and $\mathrm{H}_{2} \mathrm{O}_{2}$ are the results of such varietal performances for Swarna Sub1A. In a complication of few factors concerning oxidative stress, dehydration, photo inhibition, nutrient deficiency, specific ion toxicity etc cause almost complete collapse of cellular functionales to premature senescence in rice land races (26). However, for Swarna Sub1A, it is not ambiguous that plants would be more sensitised with $\mathrm{O}_{2}$. and $\mathrm{H}_{2} \mathrm{O}_{2}$ accumulation and thereby, a significant loss of membrane permeability might be obscured (27). The loss of membrane permeability might be accounted with an inherent phenomenon of lipid and protein oxidation under submergence (28). The Swarna Sub1A has earlier been nicely characterized with its cellular integrity for growth and development both under submergence as well as de-submergence. Still, the degenerative process leading to membrane functioning in tolerant line in the present experiment may undoubtedly confirm the roles of ROS. More so, SUB1 allele has also been influencing to the responses of ethylene sensitivity under situation of ROS activation. The later becomes an enhancer in down regulation of genes related to inter-nodal elongation rendering a suppressed growth (29). Besides the $\mathrm{O}_{2 .}$., the other one, $\mathrm{H}_{2} \mathrm{O}_{2}$ not a free radical has more been related to SUB1 QTL (30). Ethylene signaling pathway under conditions of hypoxia following aeration results in up and/or down-regulation of stressrelated genes. Lipid and protein profile and its modification as elucidated in the present experiment with PA and SA are contextual indeed. The peroxidation reaction in Swarna Sub1A with its significant variation from control might be granted as a cellular bio-marker for extent of oxidative stress. Both the moieties in cellular $\mathrm{pH}$ undergo dissociation to positively charged residues and establish electrophilic interaction with negatively charged domain of cellular membranes (31). The low yielding land races having low to moderate phrase of SUB1 allele might be more accomplished with their lesser membrane oxidation by PAs and SA. Therefore, the signalling of ROS to elicitor molecules (e.g. PA and SA) would also be relevant in submergence tolerance paths. In relation to ROS, the present experiment realised a distinct variation in antioxidation cascade are also over expressed with changes of submergence to re-aeration of the rice variety.

PA induced enhancement of antioxidative enzymes like SOD, GPX, CAT and GR have earlier been corroborated with anoxia related stress in crop plants (32). Still there is a question whether the SUB1 allele is constitutive or induces the antioxidation gene expression in nature. There is a distinct pattern and variation for the land races of rice with SUB1 or SNORKEL elements varied under submergence and de-submergence (re-aeration). Whatever the cases might be whether anaerobic signal could induce the set of gene expression (including carbohydrate catabolism) are varied with anti-oxidation genes as the plants recede the water level. Therefore, as biomarkers antioxidative proteins like SOD, GPX, CAT and GR would typify the changes of redox (oxidised: reduced) under high oxygen tension coupled with high re-aeration on de-submergence. In the present study, this is no exception of the fact that Swarna Sub1A may possess the secondary traits for anti-oxidation expression along with suppression of the growth under water. In general, there is a common observation that exogenous application of SA is manifested into total PA pull in plants (33). SA is interacted in a more complex pathway, particularly under stressful condition with other hormonal or growth regulators. In fact, SA with its glycosides has also been reported to down-regulate ethylene biosynthesis. In optimal concentration of ethylene with the salt induction is over expressed by its precursor 1-amino cyclopropane (ACC). On the other hand, ACC is the downstream moieties of S-adenosyl L-methionine (SAM). The later is shared with PA and ethylene as a common precursor. Therefore, the biosynthesis of PA and ethylene is considered to be competitive under abiotic stress. So, a line of involvement for ethylene mediated quiescence strategy found in SUB1 locus in rice may be justified with SA and PA 
(34). Moreover, the modulation of enzyme activities by PA and SA interference also demands the recognition of regulatory step(s). This may have the possibility to over-express that might circumvent the oxidative loss of plants under submergence to de-submergence.

\section{Conclusion}

The present study is dealt with physiological and cellular responses of rice cultivar possessing the SUB1 QTL. The inherent activity of SUB1 though based on a suppression of the growth of rice under water, its post submergence oxygenic stress may not be avoided. It is the ROS, the factor of submergence mediate loss of tissue and could be reversed by application of Polyamine (PA) and Salicylic acid (SA). This also conceive the probability of introduce polyamine and jasmonic acid metabolism interference to moderate the submergence stress in the genotypes. Therefore, the biochemical paths leading the anti-oxidation may be deciphered from de-submergence mediated oxidative shock and could be compared with other moderate to high yielding, however, submergence sensitive land races. Likewise, the regulatory elements for quiescence strategies compounded with mechanism of oxidative tolerance would be the key selection pressure under submergence of rice cultivars.

\section{Conflict of Interest}

The authors have no conflict of interest.

\section{Authors' Contribution}

BS conducted the whole experiment following collection of data. AKD done statistical analysis and drafted the manuscript with collection of references. MKA hypothesised, designed the experiment, discussed the findings with scientific justification and over all written the whole manuscript.

\section{Acknowledgements}

This work is acknowledged for financial support by DST-PURSE programme applicable to University of Kalyani and University Research Scholarship (URS) contingency grant of University of Kalyani.

\section{References}

1. Jones HG. Monitoring plant and soil water status: established and novel methods revisited and their relevance to studies of drought tolerance. Journal of experimental botany. 2006 Sep 15;58(2):119-30. https://doi.org/10.1093/jxb/erl118

2. Smith RD, Pregnall AM, Alberte RS. Effects of anaerobiosis on root metabolism of Zostera marina (eelgrass): implications for survival in reducing sediments. Marine Biology. 1988 May 1;98(1):131-41. https://doi.org/10.1007/BF00392668

3. Das K, Roychoudhury A. Reactive oxygen species (ROS) and response of antioxidants as ROS-scavengers during environmental stress in plants. Frontiers in Environmental Science. 2014 Dec 2;2:53. https://doi.org/10.3389/fenvs.2014.00053

4. Chaves MM, Flexas J, Pinheiro C. Photosynthesis under drought and salt stress: regulation mechanisms from whole plant to cell. Annals of botany. 2009 Feb 1;103(4):551-60. https://doi.org/10.1093/aob/mcn125

5. Garrity GM, Bell JA, Lilburn T. Family IV. Halomonadaceae Franzmann, Wehmeyer and Stackebrandt 1989, 205VP emend. Dobson and Franzmann 1996, 558. Bergey's Manual ${ }^{\circledR}$ of Systematic Bacteriology: Volume 2: The Proteobacteria, Part B: The Gammaproteobacteria. 2007 Dec 14;2:300.

6. Ellis RH, Hong TD. Temperature sensitivity of the lowmoisture-content limit to negative seed longevitymoisture content relationships in hermetic storage. Annals of botany. 2006 Feb 22;97(5):785-91. https://doi.org/10.1093/aob/mcl035

7. Tirani MM, Nasibi F, Kalantari KM. Interaction of salicylic acid and ethylene and their effects on some physiological and biochemical parameters in canola plants (Brassica napus L.). Photosynthetica. 2013 Sep 1;51(3):411-8. https://doi.org/10.1007/s11099-013-00412

8. Ghosh N, Adak MK. Effects of Putrescine on AntiOxidative Enzymes in Two Rice Cultivars Subjected to Salinity. Advances in Crop Science and Technology. 2016 Feb 17,4:210. https://doi.org/10.4172/23298863.1000210

9. Hedge JE, Hofreiter BT. Determination of reducing sugars and carbohydrates: anthrone colorimetric method. Methods in carbohydrate chemistry. 1962;1:389-90.

10. Miller GL. Estimation of reducing sugar by dinitrosalicylic acid method. Anal Chem. 1972;31:4268.

11. Kruger JE. Changes in the amylases of hard red spring wheat during grwoth and maturation. Cereal chemistry. 1972.

12. Zakaria M, Simpson K, Brown PR, Krstulovic A. Use of reversed-phase high-performance liquid chromatographic analysis for the determination of provitamin A carotenes in tomatoes. Journal of Chromatography A. 1979 Aug 1;176(1):109-17. https://doi.org/10.1016/S0021-9673(00)92091-0

13. Heath RL, Packer L. Photoperoxidation in isolated chloroplasts: I. Kinetics and stoichiometry of fatty acid peroxidation. Archives of biochemistry and biophysics. $\quad 1968 \quad$ Apr $1 ; 125(1): 189-98$. https://doi.org/10.1016/0003-9861(68)90654-1

14. Foyer $\mathrm{CH}$, Noctor G. Oxidant and antioxidant signalling in plants: a re-evaluation of the concept of oxidative stress in a physiological context. Plant, Cell \& Environment. $2005 \quad$ Aug 1;28(8):1056-71. https://doi.org/10.1111/j.1365-3040.2005.01327.x

15. Elstner EF, Heupel A. Inhibition of nitrite formation from hydroxylammoniumchloride: a simple assay for superoxide dismutase. Analytical biochemistry. 1976 Feb 1;70(2):616-20. https://doi.org/10.1016/00032697(76)90488-7

16. Ghosh N, Adak MK, Ghosh PD, Gupta S, Gupta DS, Mandal C. Differential responses of two rice varieties to salt stress. Plant Biotechnology Reports. 2011 Jan 1;5(1):89-103. https://doi.org/10.1007/s11816-010-0163-y

17. Cakmak I, Marschner H. Magnesium deficiency and high light intensity enhance activities of superoxide dismutase, ascorbate peroxidase, and glutathione reductase in bean leaves. Plant physiology. 1992 Apr 
$1 ; 98(4): 1222-7$. $222 / 06 / \$ 01.00 / 0$

18. Verma S, Dubey RS. Lead toxicity induces lipid peroxidation and alters the activities of antioxidant enzymes in growing rice plants. Plant Science. 2003 Apr 30;164(4):645-55. https://doi.org/10.1016/S01689452(03)00022-0

19. Barclay AM, Crawford RM. Plant growth and survival under strict anaerobiosis. Journal of Experimental Botany. 1982 Jun 1;33(3):541-9. https://doi.org/10.1093/jxb/33.3.541

20. Sarkar RK, Reddy JN, Sharma SG, Ismail AM. Physiological basis of submergence tolerance in rice and implications for crop improvement. Current Science. 2006 Oct 10:899-906. http://www.jstor.org/stable/24094287

21. Barar J. Cellular trafficking and subcellular interactions of cationic gene delivery nanomaterials. Journal of Pharmacy and Nutrition Sciences. 2011;1(1). http://dx.doi.org/10.6000/19275951.2011.01.01.12

22. Kathuria H, Giri J, Tyagi H, Tyagi AK. Advances in transgenic rice biotechnology. Critical Reviews in Plant Sciences. 2007 Mar 19;26(2):65-103. http://dx.doi.org/10.1080/07352680701252809

23. Barding Jr GA, Fukao T, Béni S, Bailey-Serres J, Larive CK. Differential metabolic regulation governed by the rice SUB1A gene during submergence stress and identification of alanylglycine by $1 \mathrm{H}$ NMR spectroscopy. Journal of proteome research. 2011 Nov 11;11(1):320-30. https://doi.org/10.1021/pr200919b

24. Neale PJ, Cullen JJ, Lesser MP, Melis A. Physiological bases for detecting and predicting photoinhibition of aquatic photosynthesis by PAR and UV radiation. Photosynthetic responses to the environment. 1993 Jun;33:61-77.

25. Hérouart D, Baudouin E, Frendo P, Harrison J, Santos R, Jamet A, Van de Sype G, Touati D, Puppo A. Reactive oxygen species, nitric oxide and glutathione: a key role in the establishment of the legume-Rhizobium symbiosis. Plant Physiology and Biochemistry. 2002 Aug 31;40(6):619-24. https://doi.org/10.1016/S0981-9428(02)01415-8
26. Maheswari M, Yadav SK, Shanker AK, Kumar MA Venkateswarlu B. Overview of plant stresses: Mechanisms, adaptations and research pursuit. InCrop Stress and its Management: Perspectives and Strategies 2012 (pp. 1-18). Springer Netherlands. https://doi.org/10.1007/978-94-007-2220-0_1

27. Higuchi Y. Glutathione depletion-induced chromosomal DNA fragmentation associated with apoptosis and necrosis. Journal of cellular and molecular medicine. 2004 Oct 1;8(4):455-64. https://doi.org/10.1111/j.15824934.2004.tb00470.x

28. Guo W, Ngo HH, Li J. A mini-review on membrane fouling. Bioresource technology. 2012 Oct 31;122:27-34. https://doi.org/10.1016/j.biortech.2012.04.089

29. Choi D. Ethylene-induced stem growth of deep water rice is correlated with expression of gibberellin-and abscisic acid-biosynthetic genes. Journal of Plant Biology. 2007 Oct 1;50(5):595-9. https://doi.org/10.1007/BF03030714

30. Jackson MB, Ram PC. Physiological and molecular basis of susceptibility and tolerance of rice plants to complete submergence. Annals of botany. 2003 Jan 2;91(2):227-41. https://doi.org/10.1093/aob/mcf242

31. Sakai N, Gerard D, Matile S. Electrostatics of cell membrane recognition: Structure and activity of neutral and cationic rigid push-pull rods in isoelectric, anionic, and polarized lipid bilayer membranes. Journal of the American Chemical Society. 2001 Mar 21;123(11):2517-24. https://doi.org/10.1021/ja003141

32. Tamanti F. Phytoremediation by poplar: polyphenols polyamines and oxidative damage in the response to heavy metals in in vitro and in hydroponic cultures (Doctoral dissertation, alma). https://doi.org/10.6092/unibo/amsdottorato/4374.

33. Gharbi E, Martínez JP, Benahmed H, Fauconnier ML, Lutts S, Quinet M. Salicylic acid differently impacts ethylene and polyamine synthesis in the glycophyte Solanum lycopersicum and the wild-related halophyte Solanum chilense exposed to mild salt stress. Physiologia plantarum. 2016 Oct 1;158(2):152-67. https://doi.org/10.1111/ppl.12458

34. Poór P, Kovács J, Szopkó D, Tari I. Ethylene signaling in salt stress-and salicylic acid-induced programmed cell death in tomato suspension cells. Protoplasma. $2013 \mathrm{Feb}$ 1;250(1):273-84. https://doi.org/10.1007/s00709-012-0408-4 